\title{
Response to Letter to the Editor
}

Authors: Vignesh Narasimhan FRACS ${ }^{1,2}$, Alexander Heriot MD, MBA, FRACS ${ }^{1,2}$, Satish Warrier MS, FRACS ${ }^{1,2}$

\author{
Affiliations: \\ ${ }^{1}$ Peter MacCallum Cancer Centre, Department of Surgical Oncology \\ ${ }^{2}$ Sir Peter MacCallum Dept. of Oncology, University of Melbourne
}

\section{Conflicts of interest and disclosures:}

The Authors have no conflicts of interest. There is no grant support or financial relationship associated with this study.

This manuscript has 343 words excluding references

\author{
Corresponding Author: \\ Dr Vignesh Narasimhan \\ vignesh.naras@gmail.com \\ Phone: +61 451121766; \\ Fax: +61385597709
}

This is the author manuscript accepted for publication and has undergone full peer review but has not been through the copyediting, typesetting, pagination and proofreading process, which may lead to differences between this version and the Version of Record. Please cite this article as doi: 10.1111/ans.16051

This article is protected by copyright. All rights reserved. 
We thank Dr Church for his interest in our perspective. ${ }^{1}$ The purpose of the perspective was to stimulate debate on the topical issue of the utility of complete mesocolic excision (CME) for right-sided cancers amongst the Australasian surgical community. In his reply, Church addresses the concept of the "no touch technique", a technique popularised at the Cleveland Clinic, and has been taught to many surgeons who have had the fortune of training there. The two senior authors have learned this technique in Cleveland from $\mathrm{Dr}$ Church among others and recognise that both the extent and quality of lymphadenectomy is important in standardising such an approach.

The study by Liang et $\mathrm{al}^{2}$ demonstrated that the quality of surgery in colon cancer is paramount to oncological success. The 'no touch technique' involves isolation of the cancer with early division of the feeding vessels and draining lymphatics at their origin. Application in minimally invasive surgery is difficult to compare, as demonstrated by the small proportion (13.8\%) of patients who underwent minimally invasive surgery in the study.

The evolution of surgery is an ongoing process, to improve surgical techniques that may ultimately result in improved patient outcomes. CME is an important concept in the management of right sided cancers, and we ask surgeons to give due consideration and understand its place in modern surgical treatment pathways. While BMI is an important factor in the western population, studies show that CME can be performed safely with minimally invasive techniques, with low morbidity for patients with higher BMI, when performed in a structured approach. ${ }^{3}$

The results of the recent Lancet Oncology publication are compelling, even when accounting for confounders. ${ }^{4} \mathrm{~A}$ similar difference in a chemotherapy-based study may be viewed as landmark evidence. Minimally invasive $\mathrm{CME}$ is more complex and technically challenging compared to conventional colectomy, with an expected steep learning curve. If surgeons wish to adopt this, it should be done safely with a structured training program, with appropriate proctoring and mentorship by surgeons proficient in the procedure, along with rigorous case audit through the Binational Colorectal Cancer Audit. 


\section{References}

1. Narasimhan V, Das A, Waters P, McCormick J, Heriot A, Warrier S. Complete mesocolic excision and central vascular ligation for right-sided cancers: is it time to jump on board? ANZ J Surg. 2020;90(1-2):11-2.

2. Liang J, Fazio V, Lavery I, Remzi F, Hull T, Strong S, et al. Primacy of surgery for colorectal cancer. Br J Surg. 2015;102(7):847-52.

3. Yang Y, Malakorn S, Zafar SN, Nickerson TP, Sandhu L, Chang GJ. Superior Mesenteric Vein-First Approach to Robotic Complete Mesocolic Excision for Right Colectomy: Technique and Preliminary Outcomes. Dis Colon Rectum. 2019;62(7):894-7.

4. Bertelsen CA, Neuenschwander AU, Jansen JE, Tenma JR, Wilhelmsen M, KirkegaardKlitbo A, et al. 5-year outcome after complete mesocolic excision for right-sided colon cancer: a population-based cohort study. Lancet Oncol. 2019;20(11):1556-65.

This article is protected by copyright. All rights reserved. 


\section{University Library}

\section{- M M I N E R VA A gateway to Melbourne's research publications}

Minerva Access is the Institutional Repository of The University of Melbourne

Author/s:

Narasimhan, V;Heriot, A;Warrier, S

Title:

Re: Complete mesocolic excision and central vascular ligation for right-sided cancers: is it time to jump on board? Response

Date:

2020-06-01

Citation:

Narasimhan, V., Heriot, A. \& Warrier, S. (2020). Re: Complete mesocolic excision and central vascular ligation for right-sided cancers: is it time to jump on board? Response. ANZ JOURNAL OF SURGERY, 90 (6), pp.1216-1217. https://doi.org/10.1111/ans.16051.

Persistent Link:

http://hdl.handle.net/11343/275807 